\title{
Medical symptoms associated with tobacco smoking with and without marijuana abuse among crack cocaine-dependent patients.
}

\author{
Ashwin A. Patkar \\ Thomas Jefferson University; Duke University \\ Vikas Batra \\ Thomas Jefferson University \\ Paolo Mannelli \\ Thomas Jefferson University; Duke University \\ Sarah Evers-Casey the thal wark at: https://jdc.jefferson.edu/phbfp \\ Pefren University \\ Part of the Psychiatry Commons \\ Michael Sergare how access to this document benefits you
}

Recommended Citation

See next page for additional authors

Leone, Frank T., "Medical symptoms associated with tobacco smoking with and without

marijuana abuse among crack cocaine-dependent patients." (2005). Department of Psychiatry and Human Behavior Faculty Papers. Paper 39.

https://jdc.jefferson.edu/phbfp/39

This Article is brought to you for free and open access by the Jefferson Digital Commons. The Jefferson Digital Commons is a service of Thomas Jefferson University's Center for Teaching and Learning (CTL). The Commons is a showcase for Jefferson books and journals, peer-reviewed scholarly publications, unique historical collections from the University archives, and teaching tools. The Jefferson Digital Commons allows researchers and interested readers anywhere in the world to learn about and keep up to date with Jefferson scholarship. This article has been accepted for inclusion in Department of Psychiatry and Human Behavior Faculty Papers by an authorized administrator of the Jefferson Digital Commons. For more information, please contact: JeffersonDigitalCommons@jefferson.edu. 
Authors

Ashwin A. Patkar, Vikas Batra, Paolo Mannelli, Sarah Evers-Casey, Michael J. Vergare, and Frank T. Leone 


\section{Medical Symptoms Associated with Tobacco Smoking with and without Marijuana Abuse among Crack Cocaine-dependent Patients}

Ashwin A. Patkar, M.D., Vikas Batra, M.D., Paolo Mannelli, M.D., Sarah Evers-Casey, M.P.H., Michael J. Vergare, M.D., Frank T. Leone, M.D., M.S.

Despite the widespread use of tobacco and marijuana by cocaine abusers, it remains unclear whether combined tobacco and marijuana smoking is more harmful than tobacco smoking alone in cocaine abusers. We investigated the differences in medical symptoms reported among 34 crack cocaine abusers who did not smoke tobacco or marijuana $(C), 86$ crack cocaine abusers who also smoked tobacco $(C+T)$, and 48 crack abusers who smoked both tobacco and marijuana $(C+T+M)$. Medical symptoms were recorded using a 134-item self-report instrument (MILCOM), and drug use was assessed using the Addiction Severity Index (ASI). After controlling for clinical and demographic differences, the $C+T+M$ group reported significantly more total symptoms on the MILCOM as well as on the respiratory, digestive, general, and nose=throat subscales than the $C+T$ or $C$ groups. The $C+T$ group reported higher total and respiratory and nose=throat symptoms than the $C$ group. However, the $C$ group had the highest number of mood symptoms among the three groups. The $C+T$ and $C+T+M$ groups were comparable in number of cigarettes smoked and ASI scores. Although tobacco smoking is associated with higher reports of medical problems in crack abusers, smoking both marijuana and tobacco seems to be associated with greater medical problems than smoking tobacco alone. Tobacco smoking was not related to changes in cocaine use. Also, marijuana smoking does not appear to be associated with a reduction in tobacco or cocaine use. (Am J Addict 2005; 14:43-53)

Although adult tobacco use has declined in the recent years, certain population groups, particularly those with substance dependence, have shown no appreciable reduction. (1-3) The prevalence of tobacco smoking in substance abusers is found to be 4-5 times higher than in the general population, (4-5) with smoking rates of 75-80\% reported among cocaine abusers. 3,(68) The health hazards of tobacco use among substance abusers, including premature death, have been well documented. $(9,10)$ For example, Hurt et al. (11) found that individuals treated for substance dependence continued to have a high risk of developing tobacco-related diseases and were more likely to die from tobacco- related causes than illnesses related to their primary substance of abuse.

The National Household Survey on Drug Abuse (NHSDA) (12) found that marijuana is the most commonly used illicit drug in the U.S., with a prevalence rate of 5.4\%. Marijuana users comprise nearly $75 \%$ of all illicit drug users in the U.S.; about 55\% use mostly marijuana and about $20 \%$ use marijuana along with another illicit drug. (12) Cocaine abusers in particular have been found to have very high rates of marijuana use. For example, in a study of 228 crack cocaine abusers, Gorelick et al. 6 found that $17.5 \%$ of patients had smoked only marijuana and $61 \%$ smoked tobacco and marijuana. Both tobacco and marijuana are considered to be gateway drugs for cocaine use as their use almost always precedes the use of cocaine. (13-15) Further, tobacco and marijuana use are closely associated. Among marijuana smokers, approximately $75 \%$ also smoke 
tobacco. (16) Also, analysis of the NHSDA data showed that tobacco smokers are seven times more likely to use marijuana than those who do not smoke tobacco. $(12,17,18)$ The impact of marijuana smoking on tobacco use remains unclear. While several studies have not found a decrease in tobacco smoking with concomitant marijuana use, $(19,20)$ a small study of eight patients reported that marijuana smoking was related to a significant reduction in tobacco smoking. (21) In contrast, in a large sample of 431 subjects, Ford et al. (22) reported that use of marijuana at baseline strongly correlated with continued smoking even after thirteen years. Since the first Surgeon General's report (23) on the harmful consequences of tobacco use was published over 35 years ago, the adverse medical consequences of tobacco smoking have been well established. Smokers have a ten-fold increased risk of developing lung cancer and show a 2-4 times greater risk of dying from coronary heart disease compared to non-smokers. (24) Furthermore, smoking is found to account for about $90 \%$ of cases of emphysema, (25) and maternal smoking has been linked to low birth weight babies and stillbirth. (26) Studies have also shown that chronic, habitual smoking of marijuana has adverse health effects that may be com- parable or possibly more serious than tobacco. (27-29) Marijuana smoke contains several of the carcinogenic and irritant compounds that are found in tobacco smoke. (30) In addition, compared to smoking tobacco, smoking marijuana is associated with a nearly five-fold greater increase in blood carboxyhemoglobin levels, an approximately three-fold increase in the amount of tar inhaled, and retention in the respiratory tract of one-third more tar. (31) Large scale studies have found that independent of the effects of tobacco, marijuana smoking is associated with increased risk of bronchitis, head and neck cancers, and cardiovascular and neuropsy- chiatric problems. (32-34) The data on the medical effects of smoking both marijuana and tobacco in the general population are sparse and inconsistent. For example, Gong et al. (35) reported no statistically significant differences in respiratory symptoms and lung functions between marijuana smokers, tobacco smokers, and marijuana plus tobacco smokers. In contrast, Sherman et al. (36) found adverse effect of combined marijuana and tobacco smoking on lung function tests such as diffusion capacity. Other studies suggest that the combination of marijuana and tobacco smoking may be more harmful than smoking marijuana or tobacco alone, as the combination leads to more inflammation in the lungs (37) and DNA damage. (38) Although medical problems due to the use of specific substances are well documented, there are few studies that have examined the possible additive effects of tobacco and marijuana smoking upon medical symptoms of substance abusers. We have previously reported that substance abusers who smoke tobacco report more medical symptoms when compared to non-smokers; however, these effects seemed to differ between cocaine-, alcohol-, and opiate-dependent patients. (39) In the present study, we investigated whether combined tobacco and marijuana smoking is more harmful than tobacco smoking alone in crack cocaine abusers. The sample recruited for this study was different from our previous work. 


\section{Methods}

\section{Subjects}

As a part of a National Institute on Drug Abuse-supported study on biological markers in cocaine addiction, 168 cocaine- dependent subjects were recruited from a publicly funded, university-affiliated, intensive outpatient cocaine treatment program that serves a predominantly inner-city population in Philadelphia. The study was approved by the Institutional Review Board of Thomas Jefferson University, and written informed consent was obtained from all subjects. Over $95 \%$ of cocaine- dependent patients smoked crack cocaine; therefore, only patients smoking crack cocaine were included in the study. Crack cocaine users were included if they were diagnosed with primary cocaine dependence in accordance with DSM-IV criteria. (40) Marijuana users were included if their urine screens at admission were positive for marijuana and they met DSM-IV criteria for current marijuana abuse or dependence. Tobacco smokers who fulfilled DSM-IV criteria for nicotine dependence and whose urine drug screens tested positive for nicotine were included. Patients who used other illicit drugs or alcohol were included only if their drug of choice was crack cocaine and they were not dependent on illicit drugs (except marijuana). Patients with past or present comorbid schizophrenia or bipolar disorder were excluded.

\section{Assessments}

Subjects received a standard set of assessments as part of the intake process. This included demographic data, addiction and medical history, urine drug screens, and physical examination. The subjects also completed the MILCOM, (41) a 134-item self- report questionnaire about medical symptoms relating to seventeen body organ systems: head=neck, eyes, ears, mouth, nose=throat, respiratory, cardiovascular, gastrointestinal, urinary, musculoskeletal, male genital, female genital, obstetric, skin, neurological, mood, and general. The MIL-COM is easy to administer and free of jargon, and it takes about fifteen minutes to complete. It is therefore a convenient screening tool for medical symptoms in an outpatient setting. We did not include the gender specific scales (male genital, female genital, obstetric) in our analyses and omitted items on traveling abroad and wearing seat belts, bringing the total number of endorsable items in the study to 108. Severity of substance use was assessed using the Addiction Severity Index (ASI), (42) a forty-minute structured interview assessing the severity and patterns of drug and alcohol use and impairment in employment, medical, legal, family=social, and psychiatric domains of functioning. For each problem area, it provides a subjective severity rating and a more objective composite score. It has been widely employed in clinical and research settings. Depressive symptoms were rated using the Beck Depression Inventory (BDI), (43) a 21-item, self-report questionnaire that assesses depressive symptomatology and requires about ten minutes to complete. 


\section{Assessment of Tobacco, Crack and Marijuana Use}

Individuals were initially assessed to determine whether they smoked tobacco. For smokers, the number of cigarettes smoked per day was recorded. Patients who had not smoked in the previous twelve months were considered former smokers, while individuals who had smoked fewer than 100 cigarettes in their lifetime were considered nonsmokers. The amount of crack use was recorded in grams per day, frequency as days per week, and duration as years of regular use. The amount of marijuana use was recorded as joints per day and per week, and duration as years of regular use. Joint years of use was defined as average number of joints per smoking day multiplied by years of use.

\section{Data Analysis}

Subjects were divided into cocaine alone $(\mathrm{C})$, cocaine and tobacco $(\mathrm{C} \mathrm{p} \mathrm{T})$, and cocaine, marijuana, and tobacco $(\mathrm{C} \mathrm{p} \mathrm{T} \mathrm{p} \mathrm{M)} \mathrm{groups.} \mathrm{Chi-square} \mathrm{tests,} \mathrm{independent} \mathrm{t-tests} \mathrm{(two-tailed),}$ and one way Analysis of Variance (ANOVA) were used as appropriate to examine demographic and clinical differences. The three patient groups were then compared with respect to the number of symptoms endorsed in total as well as on each of the fourteen MILCOM scales using ANOVA and Analysis of Covariance (ANCOVA), controlling for clinical and demographic differences. For this purpose, the data on clinical and demographic variables were used as a covariate while comparing medical symptoms across the three patient groups using ANCOVA. When appropriate, post-hoc Scheffe Tests (44) were conducted to tease apart significant effects. Relationships between the number of cigarettes and joints smoked and medical symptoms were examined by Pearson product moment correlation. The approach to deal with potential Type I error associated with multiple tests (fourteen subscales of MILCOM) was to initially perform a test of overall significance using total scores on MILCOM, as recommended by Cohen and Cohen. 45 Only in the case of a significant result $(\mathrm{p}<.05)$ or trend $(\mathrm{p}<.10)$ for the total scale were tests of significance performed for the subscales.

\section{RESULTS}

\section{Subjects}

Out of 258 crack cocaine-dependent patients screened, a total of 168 subjects met the inclusion criteria and were enrolled in the study. Excluded subjects were: eight patients with current major psychiatric disorder, 41 patients who also met criteria for alcohol=other illicit drug dependence (except marijuana), 32 marijuana smokers who did not meet the criteria for abuse= dependence, and nine patients who were intermittent tobacco smokers and/or primarily smoked cigars or chewed tobacco. The 168 subjects included in the study were: 34 crack cocaine abusers who did not smoke tobacco or marijuana (C), 86 crack cocaine abusers who also smoked tobacco (C p T), and 48 crack abusers who smoked both tobacco and marijuana ( $\mathrm{C} \mathrm{p} \mathrm{T} \mathrm{p} \mathrm{M).} \mathrm{The} \mathrm{sample} \mathrm{included}$ 
$114(67.8 \%)$ men and 54 (32.2\%) women; 142 (84.5\%) were African-American, 20 (11.9\%) were Caucasian, and 6 (3.6\%) were Hispanic. The demographic and clinical differences between the three groups are summarized in Table 1. As seen in Table 1, the marijuana- smoking patients were significantly younger (as expected) than those who used tobacco and cocaine or cocaine alone, and the $\mathrm{C}+\mathrm{T}+\mathrm{M}$ patients had a shorter duration of cocaine use than the $\mathrm{C}+\mathrm{T}$ and $\mathrm{C}$ groups. Those who concurrently used tobacco and marijuana reported lower scores on the Beck Depression (BDI) than those who used cocaine alone. Amount of cocaine use, ASI scores, and number of cigarettes smoked did not differ between the three groups. We examined whether medical symptoms among our subjects were related to demographic variables. The results showed that age, gender, or race were not significantly correlated with the total number of medical symptoms on the MILCOM ( $\mathrm{r}<.12$, v $2<1.46, \mathrm{p}>.05$ in each case).

\section{$\underline{\text { Tobacco and Marijuana Smoking Patterns Among Cocaine Abusers }}$}

One hundred and thirty four (79.8\%) subjects were current tobacco smokers. On average, patients smoked nearly sixteen cigarettes per day for about 24 years. The proportion of men (78.6\%) and women $(82.1 \%)$ who were smokers did not differ significantly. Similarly, no significant differences were found between African-American (79.2\%) and Caucasian (80.9\%) subjects with respect to rate of smoking $(\mathrm{v} 2=0.31, \mathrm{df}=1, \mathrm{p}>.05)$ and number of cigarettes smoked per day $(\mathrm{AA}=15.4$, Caucasians $=16.9 ; \mathrm{t}=1.31, \mathrm{df}=160, \mathrm{p}>.05)$. Forty eight $(28.6 \%)$ of cocaine-dependent patients smoked marijuana regularly over a year. The average number of marijuana joints smoked per week was eight, the average frequency was three times a week, the number of joints on smoking days averaged 2.5, and the average duration of regular use was fifteen years. The mean age of beginning regular marijuana use was about seventeen years. There were no significant gender or ethnic differences in marijuana use ( $\mathrm{v} 2<1.48$, df $=1$, $\mathrm{p}>.05$ in each case). The pattern of marijuana use in our sample shows certain similarities as well as differences when compared to data in the literature. For example, in a study of 228 cocaine smokers from the Los Angeles Area, Gorelick et al. 6 reported that $61 \%$ had a lifetime history of both marijuana and tobacco use, $17.5 \%$ smoked marijuana only, and $17 \%$ smoked tobacco only. Although these rates of marijuana use seem higher than that observed in our sample, we examined current rates in contrast to Gorelick et al., who studied lifetime rates. While the mean of age of onset (17.7 years) and average amount of use (6.4 joints per week and 2.2 joint per smoking day) of marijuana use in this study were similar to that seen in our subjects, cocaine users in Gorelick et al.'s study had a higher joint year history (average 50.7 years), reflecting heavier use compared to our sample (average 37 years). 


\section{Symptom Differences among Cocaine, Cocaine and Tobacco, and Cocaine, Tobacco and Marijuana Groups}

Analysis of variance revealed a significant difference in the total symptoms reported by the three groups, with the $\mathrm{C}+\mathrm{T}+\mathrm{M}$ smoking patients reporting the highest number of symptoms $(\mathrm{F}(2,166)=6.06, \mathrm{p}<.01)$. As shown in Table 2 , the $\mathrm{C}+\mathrm{T}+\mathrm{M}$ patients also reported the highest number of symptoms on the respiratory, nose-throat, digestive and general subscales; however, the cocaine patients reported the highest symptoms on the mood scale. Since the $\mathrm{C}$ patients were significantly younger and had higher depression (BDI) scores than $\mathrm{C}+\mathrm{T}$ or $\mathrm{C}+\mathrm{T}$ $+\mathrm{M}$ patients, we examined whether age or mood symptoms could have affected the level of health complaints. For this purpose, the data were reanalyzed, covarying for age and BDI scores. The ANCOVA analysis showed that the between-group differences in MILCOM scores continued to remain significant after controlling for age and depression $(\mathrm{F}[2,164]$ ranged from 5.83 to $3.42, \mathrm{p}<.01)$. In fact, cocaine users who smoked marijuana and tobacco, despite experiencing less depressive symptoms and being younger, reported more medical problems than individuals who only smoked cocaine. Therefore, mood symptoms or age did not appear to explain the differences in reporting of medical problems among the three groups. We also examined whether alcohol use affected the findings, using ASI alcohol composite scores as a covariate. The analysis showed that the direction and strength of differences in total MILCOM symptoms between the three groups remained unchanged after controlling for alcohol $(\mathrm{F}[2,164]$ $=6.39, \mathrm{p}<.01)$.

Post hoc (Scheffe) tests were then carried out to detect differences among the three drug groups. As summarized in Table 2, the $\mathrm{C}+\mathrm{T}+\mathrm{M}$ group reported significantly more symptoms on the total scale as well as on the respiratory, digestive, general, and nose-throat subscales than the $\mathrm{C}$ $+\mathrm{T}$ or $\mathrm{C}$ groups, while the $\mathrm{C}+\mathrm{T}$ group reported higher total and respiratory and nose throat symptoms than the $\mathrm{C}$ group ( $\mathrm{F}$ ranged from 6.06 to $3.48, \mathrm{p}<.01-<.05$ ). However, the $\mathrm{C}$ group reported higher mood symptoms than the $\mathrm{C}+\mathrm{T}$ and the $\mathrm{C}+\mathrm{T}+\mathrm{M}$ group. Among patients who smoked tobacco $(n=134)$, we examined the correlation between pack years of smoking (packs per day x years of smoking; mean, 36 years) and MILCOM scores after controlling for marijuana use using tests of partial correlation. While a trend was observed between pack years and total symptoms $(\mathrm{r}=.23, \mathrm{p}=.08)$, a significant positive correlation was obtained between pack years and scores on the respiratory $(\mathrm{r}=.29, \mathrm{p}<.05)$ and nose-throat scales $(\mathrm{r}=.28, \mathrm{p}<.01)$. No significant correlations were obtained with scores on the remaining MILCOM systems (all $\mathrm{r}<$ $0.18, \mathrm{p}>.05)$. However, no significant correlation was observed between joint years of marijuana use (joints per day x years of use; mean, 37.5 years) and total or subscale scores on the MILCOM (all $\mathrm{r}<.11, \mathrm{p}>.05)$ among marijuana smokers $(\mathrm{n}=48)$ after controlling for tobacco use. Twenty six (15.4\%) of patients had a history of chronic medical diseases, such as asthma, hypertension, and diabetes, or were taking medications for their medical conditions. One patient had tested positive for HIV infection and hepatitis exposure, and two patients had a history of only hepatitis exposure. There were no significant differences in the history of medical disease among $\mathrm{C}$ patients $(\mathrm{n}=4,11.7 \%), \mathrm{C}+\mathrm{T}$ patients $(\mathrm{n}=16,18.6 \%)$, and the $\mathrm{C}+\mathrm{T}+\mathrm{M}$ patients $(\mathrm{n}$ $=6,12.5 \%)(\mathrm{v} 2=2.31, \mathrm{df}=2, \mathrm{p}=.19)$. 


\section{DISCUSSION}

Our results show that crack cocaine abusers who smoke tobacco report more medical symptoms than nonsmokers. Moreover, the regular use of both marijuana and tobacco is associated with higher reports of medical symptoms than the use of tobacco alone in this population. The findings suggest that while tobacco use is associated with greater medical problems, concomitant use of tobacco and marijuana may have additive harmful effects in crack cocaine abusers. Demographic and clinical variables such as severity and pattern of cocaine use were unlikely to be confounders because the three patient groups were largely similar across these measures. Also, the higher depression scores in cocaine patients are not likely to have led to underreporting of symptoms because depressed patients generally report higher, not lower, somatic symptoms than non-depressed patients. Furthermore, we statistically controlled for the effect of depression on the relationship between the primary and dependent variables. It is also worth noting that significant differences between tobacco and marijuana users and nonusers were observed across respiratory, nose-throat, and gastrointestinal systems, organ systems that have been reported to be more commonly affected by both tobacco and marijuana smoking. $(27,29)$ Consistent with the literature, (46) we found a significant correlation between the pack years of tobacco smoking and respiratory and nose-throat symptoms in a crack-using population. Because cocaine abusers tend to smoke heavily and have lower quit rates than the general population, it is likely that their risk for developing tobacco-related medical diseases is comparable to (if not higher than) the general population. Not surprisingly, despite a mean age of less than 40 years, about $15 \%$ of patients suffered from medical diseases. Even more troubling is the possibility that smoking-related medical illnesses may become increasingly evident as the cocaine-abusing population grows older, as the risk of pulmonary and cardiovascular illnesses have been found to be associated with both duration and severity of smoking. $(46,47)$ While we failed to find a difference in rates of medical diseases in the three groups, the absolute numbers of affected subjects was small, and the data on medical diseases were cross-sectional and obtained from chart review. Longitudinal studies may be required to clarify the extent to which substances of abuse interact with tobacco smoking to increase the risk for medical illnesses in a substance-dependent population. Contrary to our expectations, joint years of marijuana use were not correlated with number of medical symptoms. This might be because the population we studied was younger, most patients were not daily marijuana users, and the joint year history of marijuana (average 37 years) was not severe enough to observe possible relationships. For example, Fligiel et al. (48) found that cocaine users with an average of fifty joint years of marijuana use showed evidence of bronchial injury. Also, although we statistically controlled for tobacco use, we did not have a cocaine and marijuana group; therefore, the possibility of tobacco use as a possible confounder cannot be excluded. Additional findings from the study also deserve comment. The $79 \%$ prevalence of nicotine dependence in our sample attests to the widespread addiction to tobacco among cocaine-dependent patients and is consistent with published data in outpatient clinics. $(49,50)$ Interestingly, there was no difference in the number of cigarettes smoked or severity of cocaine use between cocaine users who smoked tobacco and those who smoked both tobacco and marijuana. Cocaine use between those who only smoked crack and 
those who smoked crack and tobacco was also similar. Although the cross-sectional nature of data limits definitive conclusions, this seems to suggest tobacco use is not related to changes in cocaine use; likewise, marijuana use does not appear to be related to a reduction in tobacco or cocaine use. This additive pattern of use could also explain the higher medical symptoms in the tobacco and tobacco/marijuana groups. Finally, it is also important to note that cocaine abusers as a group had many medical complaints and endorsed an average of nearly 25 symptoms, attesting to the poor health of this population. This underscores the need for medical assessments to be an integral part of chemical dependency treatment programs. Our findings should be interpreted in light of certain methodological limitations. First, we studied self-reports of symptoms and did not collect physical examination and laboratory data. Though the MILCOM has been validated in psychiatric and non-psychiatric settings, 41 like other self-report instruments, it may be influenced by subjective factors such as perceptions about physical health and subject to recall bias. Second, because patients were recruited from a clinical program, a significant proportion abused other substances, particularly alcohol. While patients who were dependent on alcohol were excluded and we used statistical tests to control for alcohol use, it is possible that concurrent alcohol use might have affected the results. Third, we did not have a comparison group of cocaine and marijuana smokers because most of such patients invariably smoked tobacco. Such a group may have better clarified the relationship between cocaine, tobacco, and marijuana. Finally, the study was cross-sectional in nature; therefore, the directionality of relationships needs to be confirmed by longitudinal studies. In conclusion, our findings support a relationship between tobacco and marijuana smoking and medical problems among cocaine abusers. Also, neither marijuana use nor tobacco use appears to reduce cocaine use, and marijuana use does not seem to decrease tobacco use. Medical illnesses make the treatment of substance abusers complicated and expensive, a particular concern in today's climate of cost-containment; therefore, cocaine treatment programs should effectively address both tobacco and marijuana use in their patients. Further research in this area should examine the relationship of drug use with objective assessments of health status to better understand the medical consequences of substance abuse.

This research was supported by grant KO8DA00340-02 from the National Institute on Drug Abuse, Bethesda, Md. (Dr. Patkar). The authors thank Cynthia Purcell and Stephen $P$. Weinstein for recruitment.

\section{REFERENCES}

1. Hays LR, Farabee D, Miller W. Caffeine and nicotine use in an addicted population. J Addict Dis. 1998; 17:47-54.

2. Hughes JR, Hatsukami DK, Mitchell JE, et al. Prevalence of smoking among psychiatric outpatients. Am J Psychiatry. 1986;143: 993-997.

3. Budney AJ, Higgins ST, Hughes JR, et al. Nicotine and caffeine use in cocaine-dependent individuals. J Subst Abuse. 1993;5:117-130. 
4. Kalman D. Smoking cessation treatment for substance misusers in early recovery: a review of the literature and recommendations for practice. Subst Use Misuse. 1998;33:2021-2047.

5. Kozlowski LT, Wilkinson DA, Skinner W, et al. Comparing tobacco cigarette dependence with other drug dependencies: greater or equal "difficulty quitting'" and "urges to use," but less "pleasure" from cigarettes. JAMA. 1989;261:898-901.

6. Gorelick DA, Simmons MS, Carriero N, et al. Characteristics of smoked drug use among cocaine smokers. Am J Addict. 1997;6:237-245.

7. Roll JM, Higgins ST, Budney AJ, et al. A comparison of cocaine-dependent cigarette smokers and non-smokers on demographic, drug use, and other characteristics. Drug Alcohol Depend. 1996;40:195-201.

8. Sees KL, Clark HW. When to begin smoking cessation in substance abusers. J Subst Abuse Treat. 1993;10:189-195.

9. Patkar AA, Sterling RC, Leone FT, et al. Relationship between tobacco smoking and medical symptoms among cocaine-, alcohol-, and opiate-dependent patients. Am J Addict. 2002;11:209-218.

10. Miller NS, Gold MS. Comorbid cigarette and alcohol addiction: epidemiology and treatment. J Addict Dis. 1998;17:47-54.

11. Hurt RD, Offord KP, Gomez-Dahl L, et al. Mortality following inpatient addictions treatment: role of tobacco use in a community-based cohort. JAMA. 1996;275:10971103.

12. Substance Abuse and Mental Health Services Administration. Results from the 2001 National Household Survey on Drug Abuse: Vol. I. Summary of National Findings. NHSDA Series H-17, DHHS Publication No. SMA 02-3758. Rockville, Md.: Office of Applied Studies; 2002.

13. Kandel DB, Yamaguchi K, Chen K. Stages of progression in drug involvement from adolescence to adulthood: further evidence for the gateway theory. J Stud Alcohol. 1992;53:447-457.

14. Yamaguchi K, Kandel DB. Patterns of drug use from adolescence to young adulthood: II. sequences of progression. Am J Public Health. 1984;74:668-672.

15. Ellickson PL, Hays RD, Bell RM. Stepping through the drug use sequence: longitudinal scalogram analysis of initiation and regular use. J Abnorm Psychol. 1992;101:441-451.

16. Substance Abuse and Mental Health Services Administration. Results from the 1997 National Household Survey on Drug Abuse. DHHS Publication No. SMA 98-3250. Rockville, Md.: Office of Applied Studies; 1998.

17. Merrill JC, Kleber HD, Shwartz M, et al. Cigarettes, alcohol, marijuana, other risk behaviors, and American youth. Drug Alcohol Depend. 1999;56:205-212.

18. Gfroerer JC, Wu LT, Penne MA. Initiation of Marijuana Use: Trends, Patterns, and Implications. Analytic Series: A-17, DHHS Publication No. SMA 02-3711. Rockville, Md.: Substance Abuse and Mental Health Services Administration, Office of Applied Studies; 2002.

19. Nemeth-Coslett R, Henningfield JE, O’Keeffe MK, et al. Effects of marijuana smoking on subjective ratings and tobacco smoking. Pharmacol Biochem Behav. 1986;25:659-665.

20. Mello NK, Mendelson JH, Sellers ML, et al. Effect of alcohol and marijuana on tobacco smoking. Clin Pharmacol Ther. 1980;27:202-209.

21. Kelly TH, Foltin RW, Rose AJ, et al. Smoked marijuana effects on tobacco cigarette Smoking behavior. J Pharmacol Exp Ther. 1990;252:934-944. 
22. Ford DE, Vu HT, Anthony JC. Marijuana use and cessation of tobacco smoking in adults from a community sample. Drug Alcohol Depend. 2002;67:243-248.

23. U.S. Department of Health and Human Services. The health consequences of smoking: nicotine addiction - a report of the Surgeon General. CDC publication no 88-8046. Washington, DC: US Government Printing Office; 1988.

24. U.S. Department of Health and Human Services. Reducing the health consequences of smoking: 25 years of progress. A Report of the Surgeon General. CDC publication no 89-8411. Washington, DC: US Government Printing Office; 1989.

25. Lacroix AZ, Lang J, Scheer P. Smoking and mortality among older men and women in three communities. N Eng J Med. 1991;324:1619-1625.

26. Fielding J. Smoking: health effects and control. N Eng J Med. 1985;313:491-498.

27. Tashkin DP, Baldwin GC, Sarafian T, et al. Respiratory and immunologic consequences of marijuana smoking. J Clin Pharmacol. 2002;42(11 Suppl):71S-81S.

28. Sidney S. Cardiovascular consequences of marijuana use. J Clin Pharmacol . 2002;42(11 Suppl): 64S-70S.

29. Hall W, Solowij N. Adverse effects of cannabis. Lancet. 1998;352:1611-1616.

30. Hoffman D, Brunnemann KD, Gori GB, et al. On the carcinogenicity of marijuana smoke. In: Runeckles VC, ed. Recent Advances in Phytochemistry. New York: Plenum; 1975:63-81.

31. Wu TC, Tashkin DP, Djahed B, et al. Pulmonary hazards of smoking marijuana as compared With tobacco. N Engl J Med. 1988;318:347-351.

32. Polen MR, Sidney S, Tekawa IS, et al. Healthcare use by frequent marijuana smokers who do not smoke tobacco. West J Med. 1993;158:596-601.

33. Zhang ZF, Morgenstern H, Spitz MR, et al. Marijuana use and increased risk of squamous cell carcinoma of the head andneck. Cancer Epidemiol Biomarkers Prev. 1999;8:1071-1078.

34. Tashkin DP. Pulmonary complications of smoked substance abuse. We st J Med. 1990;152:525-5 30.

35. Gong H, Jr., Fligiel S, Tashkin DP, et al. Tracheobronchial changes in habitual, heavy smokers of marijuana with and without tobacco. Am Rev Respir Dis. 1987;136:142-149.

36. Sherman MP, Roth MD, Gong H, Jr., et al. Marijuana smoking, pulmonary function, and lung macrophage oxidant release. Pharmacol Biochem Behav. 1991;40:663-669.

37. Roth MD, Arora A, Barsky SH, et al. Airway inflammation in young marijuana and tobacco smokers. Am J Respir Crit Care Med. 1998;157:928-937.

38. Sherman MP, Aeberhard EE, Wong VZ, et al. Effects of smoking marijuana, tobacco, or cocaine alone or in combination on DNA damage in human alveolar macrophages. Life Sci. 1995;56:2201-2207.

39. Patkar AA, Lundy A, Leone FT, et al. Tobacco and alcohol use and medical symptoms among cocaine-dependent patients. Subst Abuse. 2002;23:105-114.

40. American Psychiatric Association. Diagnostic and Statistical Manual of Mental Disorders . 4th ed. Washington, DC: American Psychiatric Association; 1994.

41. MILCOM. A Patient Database System for Improved Health Care. Rev. ed. Chicago, Illinois: Hollister, Inc; 1985.

42. McLellan AT, Luborsky L, Cacciola J, et al. The fifth edition of the Addiction Severity Index: cautions, additions, and normative data. J Nerv Mental Dis. 1992;168:26-33.

43. Beck AT, Steer RA. Beck Depression Inventory: The Psychological Corporation. San 
Antonio, Tex.: Harcourt, Brace and Jovanovich; 1987.

44. Scheffe H. The Analysis of Variance. New York: Wiley; 1959.

45. Cohen J, Cohen J. Applied Multiple Regression: Correlation for the Behavioral Sciences. Hillsdale, NJ: L. Erlbaum Associates; 1983.

46. Seidman H. Age of exposure versus years of exposure. Nat Cancer Inst Monogra. 1985; 67:205-209.

47. Anthonsien NR, Connett JE, Kiley JP, et al. Effects of smoking intervention and the use of an inhaled bronchodilator on the rate of decline of FEV1: the lung health study. JAMA. 1994;272:1497-1505.

48. Fligiel SE, Roth MD, Kleerup EC, et al. Tracheobronchial histopathology in habitual smokers of cocaine, marijuana, and=or tobacco. Chest. 1997;112:319-326.

49. Hughes JR. An overview of nicotine use disorders for alcohol/drug abuse clinicians. Am J Addict. 1996;5:262-274.

50. Sterling RC, Gottheil E, Weinstein SP, et al. The effect of a no-smoking policy on recruitment and retention in outpatient cocaine treatment. J Addict Dis. 1994;13:161- 